\title{
Physician-related barriers to communication and patient- and family-centred decision-making towards the end of life in intensive care: a systematic review
}

\author{
Mieke Visser ${ }^{1}$, Luc Deliens ${ }^{1,2}$ and Dirk Houttekier ${ }^{1 *}$
}

\begin{abstract}
Introduction: Although many terminally ill people are admitted to an intensive care unit (ICU) at the end of life, their care is often inadequate because of poor communication by physicians and lack of patient- and family-centred care. The aim of this systematic literature review was to describe physician-related barriers to adequate communication within the team and with patients and families, as well as barriers to patient- and family-centred decision-making, towards the end of life in the ICU. We base our discussion and evaluation on the quality indicators for end-of-life care in the ICU developed by the Robert Wood Johnson Foundation Critical Care End-of-Life Peer Workgroup.

Method: Four electronic databases (MEDLINE, Embase, CINAHL and PsycINFO) were searched, using controlled vocabulary and free text words, for potentially relevant records published between 2003 and 2013 in English or Dutch. Studies were included if the authors reported on physician-related and physician-reported barriers to adequate communication and decision-making. Barriers were categorized as being related to physicians' knowledge, physicians' attitudes or physicians' practice. Study quality was assessed using design-specific tools. Evidence for barriers was graded according to the quantity and quality of studies in which the barriers were reported.

Results: Of 2,191 potentially relevant records, 36 studies were withheld for data synthesis. We determined 90 barriers, of which 46 were related to physicians' attitudes, 24 to physicians' knowledge and 20 to physicians' practice. Stronger evidence was found for physicians' lack of communication training and skills, their attitudes towards death in the ICU, their focus on clinical parameters and their lack of confidence in their own judgment of their patient's true condition.

Conclusions: We conclude that many physician-related barriers hinder adequate communication and shared decision-making in ICUs. Better physician education and palliative care guidelines are needed to enhance knowledge, attitudes and practice regarding end-of-life care. Patient-, family- and health care system-related barriers need to be examined.
\end{abstract}

\section{Introduction}

Almost 30\% of the Medicare beneficiaries in the United States are admitted to an intensive care unit (ICU) in the last phase of their lives [1]. The conclusion of the SUPPORT study investigators in 1995 was that many patients in ICUs receive unwanted life-sustaining treatments and insufficient palliative care at the end of their lives [2]. In a survey of 82 adult ICUs in 9

\footnotetext{
* Correspondence: dirk.houttekier@vub.ac.be

${ }^{1}$ End-of-Life Care Research Group, Vrije Universiteit Brussel (VUB) and Ghent University, Laarbeeklaan 103, B-1090 Brussels, Belgium

Full list of author information is available at the end of the article
}

European countries plus Israel, shortcomings were perceived in ICU care by 1 in 3 physicians for at least 1 patient on the day of the survey in 2011 [3]. Perceived disproportionate care was the most common shortcoming indicated by physicians, and 'too much care' was reported in $89 \%$ of those cases. Decisions about end-of-life care were most often reported as being made too late or too infrequently, and nurses as well as physicians were greatly distressed by the perception of inappropriate care.

Death in an ICU is often described as a devastating experience for patients and their families, with patients remaining dependent on intensive life support care, neither 
dying nor recovering. Expectations are still unrealistically high among patients and their families and also among physicians $[4,5]$. Continuing life-sustaining treatments without clinical improvement causes suffering to patients and deprives them and their families of palliative care, deprives them and their families of honest prognostic information, and reduces patients' time to prepare for dying and their families' time to prepare for bereavement $[4,6]$.

End-of-life care in ICUs is often inadequate because of factors such as lack of communication between patients and health care providers, lack of patient- and family-centred care and lack of emotional and psychosocial support. It is apparent that some of these factors are due to physician-related barriers, many of which have been reported in the scientific literature [6,7]. ICU physicians are unable to provide treatment according to a patient's wishes when the goals of care and the treatment preferences of the patient are not clear and treatment decisions are not shared with the patient and the patient's family. As a result, the patient's quality of life may be harmed. This is why patients and families are currently expressing their wishes for better communication and a larger role in the treatment decision-making process and asking ICU clinicians to respond to their palliative care needs [8].

The Robert Wood Johnson Foundation (RWJF) Critical Care End-of-Life Peer Workgroup identified seven specific domains of ICU palliative care quality, including adequate communication within the team and with patients and families as well as facilitating patient- and family-centred decision-making [9]. In a multicentre study, ICU patients and families expressed strong agreement about the importance of communication and patient- and family-centred decision-making in ICU end-of-life care. Their responses were collected and organised within two domains: communication and decision-making. (1) Adequate communication by clinicians was defined as timely, ongoing, clear, complete, compassionate and focused on the patient's condition, prognosis and treatment. (2) Adequate patient-focused medical decision-making was defined as being aligned with the patient's values, care goals, treatment and preferences $[6,10]$. Within these two domains, 23 quality indicators (QIs) were developed (10 for communication within the team and with patients and their families and 13 for patient- and family-centred decision-making) through a literature review and expert consensus [11].

\section{Quality indicators for communication}

The following are the 10 QIs used to evaluate communication within the team and with patients and their families:

1. Meet as interdisciplinary team to discuss the patient's condition, clarify goals of treatment, and identify the patient's and family's needs and preferences.
2. Address conflicts among the clinical team before meeting with the patient and/or family.

3. Utilize expert clinical, ethical, and spiritual consultants when appropriate.

4. Recognize the adaptations in communication strategy required for patients and families according to the chronic versus acute nature of illness, cultural and spiritual differences, and other influences.

5. Meet with the patient and/or family on a regular basis to review patient's status and to answer questions.

6. Communicate all information to the patient and family, including distressing news, in a clear, sensitive, unhurried manner, and in an appropriate setting.

7. Clarify the patient's and family's understanding of the patients' condition and goals of care at the beginning and end of each meeting.

8. Designate primary clinical liaison(s) who will communicate with the family daily.

9. Identify a family member who will serve as the contact person for the family.

10. Prepare the patient and family for the dying process.

\section{Quality indicators for patient- and family-centred decision-making}

The following are the 13 QIs used to evaluate patient- and family-centred decision-making:

11. Recognize the patient and family as the unit of care. 12. Assess the patient's and family's decision-making style and preferences.

13. Address conflicts in decision making within the family.

14. Assess, together with appropriate clinical consultants, the patient's capacity to participate in decision making about treatment and document assessment.

15. Initiate advance care planning with the patient and family.

16. Clarify and document the status of the patient's advance directive.

17. Identify the healthcare proxy or surrogate decision maker.

18. Clarify and document resuscitation orders.

19. Assure patients and families that decision making by the healthcare team will incorporate their preferences.

20. Follow ethical and legal guidelines for patients who lack both capacity and a surrogate decision maker.

21. Establish and document clear, realistic, and appropriate goals of care in consultation with the patient and family.

22. Help the patient and family assess the benefits and burdens of alternative treatment choices as the patient's condition changes.

23. Forgo life-sustaining treatments in a way that ensures patient and family preferences are elicited and respected. 


\section{Objectives and research questions}

Establishing scientific evidence about the barriers that hinder ICU physicians in communication and shared end-of-life decision-making is important to improve the quality of end-of-life care of terminally ill ICU patients. Therefore, the objective of this systematic review was to describe physician-related and physician-reported barriers to the QIs for adequate communication within the team and with patients and families, as well as adequate patient and family-centred decision-making towards the end of life in the ICU as described by the End-of-Life Peer Workgroup of the RWJF.

The following are the specific research questions we sought to answer in this systematic literature review: (1) What are the physician-related and physician-reported barriers to communication within the team and with patients and families in end-of-life care in the ICU according to the 10 QIs for communication within the team and with patients and families in end-of-life care in the ICU, as developed by the RWJF? (2) What are the physician-related and physician-reported barriers to patient- and family-centred decision-making in end-of-life care in the ICU according to the 13 QIs for patient- and family-centred decision-making in end-of-life care in the ICU, as developed by the RWJF?

\section{Material and methods}

\section{Ethics}

Because of the nature of this study, which is a systematic literature review, ethical approval was not required.

\section{Search strategy}

The electronic databases MEDLINE, Embase, CINAHL and PsycINFO were searched for study reports published between 2003 and August 2013 in Dutch or English. We used controlled vocabulary and free text words, including: 'physicians', 'palliative care', 'advance care planning', 'terminal care', 'terminally ill', 'critical care' and 'intensive care units' (Additional file 1).

\section{Criteria for eligibility of studies Inclusion criteria}

The following were the study inclusion criteria:

- The study addressed a clear research question or objective, and primary collected qualitative or quantitative data were used.

- ICU physicians treating adult patients were reported. Intensive care physicians were defined as attending physicians, critical care fellows, resident physicians or consultants. In studies that included various types of intensive care clinicians, separate results for physicians had to have been reported.
- The report was on physician communication within the team and with patients and families or on patient and family-centred decision-making towards the end of life of patients in an ICU.

- The report was on physician-related barriers to communication and patient and family-centred decision-making as described by the physicians themselves (physician-reported) and not by other caregivers of the ICU-team (for example, nurses), by patients or by proxies or relatives. The focus was on barriers that can be changed; therefore age, sex and background of the physicians were not included as barriers.

\section{Exclusion criteria}

The following were the study exclusion criteria:

- The report was on medical students, nurses or patients and their families.

- The report was on physicians in nonadult ICUs (for example, neonatal ICU).

- The study had a quality assessment score of 5 or lower assigned independently by MV and $\mathrm{DH}$.

\section{Study selection}

Duplicates of the retrieved records were removed. MV and DH independently examined titles and abstracts of the retrieved records, using a piloted form, to exclude obviously irrelevant records. Disagreement was resolved by consensus, and a third reviewer (LD) was involved for arbitration when necessary.

In the next step of the study selection procedure, the eligibility of retrieved studies was examined independently by MV and DH using a piloted form. When necessary, a third reviewer (LD) was involved for arbitration.

\section{Data collection}

The characteristics of the included studies were extracted to a piloted data extraction form. Physician-related and physician-reported barriers for each of the 10 QIs for communication within the ICU team and with patients and their families, as well as for each of the 13 QIs for patient and family-centred decision-making in end-of-life care in ICU [11], were extracted independently by MV and DH. Barriers were categorized on the basis of whether they related to the physician's knowledge, attitudes or practice, according to a model developed by Cabana and colleagues [12]. In cases of disagreement, a third reviewer (LD) was involved for arbitration.

\section{Quality assessment and grading evidence}

The quality of studies with a qualitative research design was assessed using the dedicated tool from the Critical Appraisal Skills Programme [13]. For appraisal of the 
quantitative studies (all identified eligible quantitative studies were surveys), a survey-specific appraisal tool developed by the Center for Evidence-Based Management was used [14]. Both appraisal tools address the appropriateness of the research method in relation to the study objectives, ethical issues and quality of the data collection and analysis. Quality assessment scores were assigned independently by MV and DH. In cases of disagreement, a third reviewer (LD) was involved for arbitration. For both qualitative and quantitative studies, the total quality assessment scores are presented as scores on a scale from 0 to 10 . Studies with assessment scores from 8 to 10 were qualified as high-quality studies; those with scores of 6 to 7 were considered medium-quality studies; and those with scores equal to or lower than 5 were classified as low-quality studies. Low-quality studies were excluded from data synthesis. Barriers reported in two or more high-quality studies qualified as stronger evidence. Barriers reported in one high-quality study and one medium-quality study, or in one high-quality study or in two or more medium-quality studies, were graded as medium evidence. Barriers reported in one medium-quality study were graded as weak evidence (Figure 1).

\section{Results}

\section{Study selection}

From the electronic database searches, a total of 2,191 records were retrieved. The breakdown was 465 from MEDLINE, 1,285 from Embase, 120 from PsycINFO and 321 from CINAHL (Figure 2). After removal of duplicates $(n=667)$ and obviously irrelevant records $(n=1,459), 65$ full-text articles were assessed for eligibility. Of those 65 , one study did not meet the quality requirements; 9 did not report on physician communication within the team or with patients and families, or on patient- and family-centred decisionmaking towards the end of life of patients in the ICU; and 19 did not report on physician-related barriers reported by the physicians themselves. Thus, 36 studies met all the inclusion criteria and were used for data synthesis.

Characteristics and quality assessment of included studies Of the 36 included studies, 18 were qualitative studies and 18 were surveys (Table 1). Fourteen were conducted in the United States, five were carried out in Canada, 4 included combined results from several European countries, 3 were done in Germany, 2 were conducted in the United Kingdom and 1 each were carried out in Australia, Poland, China, Greece, Austria, Ireland, Hungary and the West Indies. Quality assessment scores varied between 6.5 and 9.5 for qualitative studies and 6 or 7 for quantitative studies.

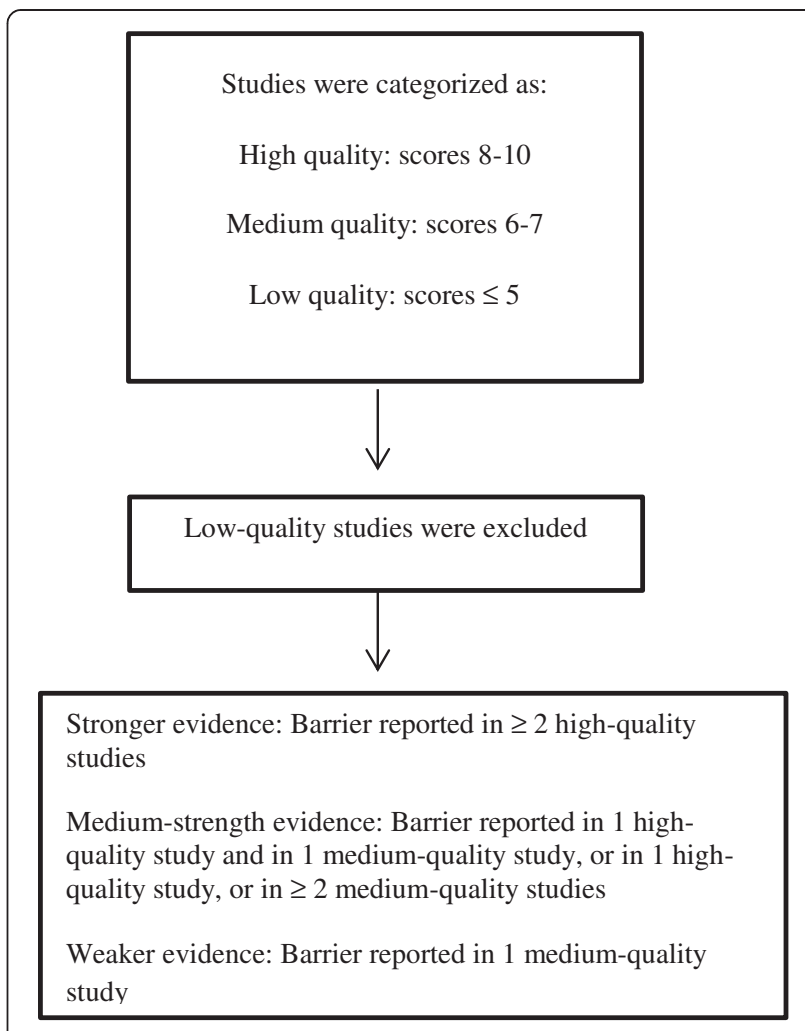

Figure 1 Quality assessment and grading of evidence.

\section{Barriers}

All the barriers reported by ICU physicians were categorized by QI as developed by Clarke and colleagues [11] according to barriers related to the knowledge, attitudes and practices of physicians [12]. Ninety different barriers were identified, among which 24 related to physician knowledge (Table 2), 46 to physician attitudes (Table 3) and 20 to physician practice (Table 4). Stronger evidence was found for 8 specific barriers (all related to physician attitudes), medium evidence for 39 and weak evidence for 43 .

\section{Barriers with regard to physicians' knowledge}

Barriers with regard to physicians' knowledge were identified for 8 of the 23 QIs. Because not many barriers were identified per QI, almost identical barriers with low- or medium-quality evidence were compared and combined across the QIs.

Across QIs, strong evidence was found for the barrier of lack of communication training and skills in end-oflife discussions in general [42] and for QIs 2, 5, 21, 22 and $23[19,22,26,31,36]$, including how to communicate to patients and their families the futility of further treatment.

Meet as interdisciplinary team to discuss the patient's condition, clarify goals of treatment, and identify the patient's and family's needs and preferences (QI 1) 


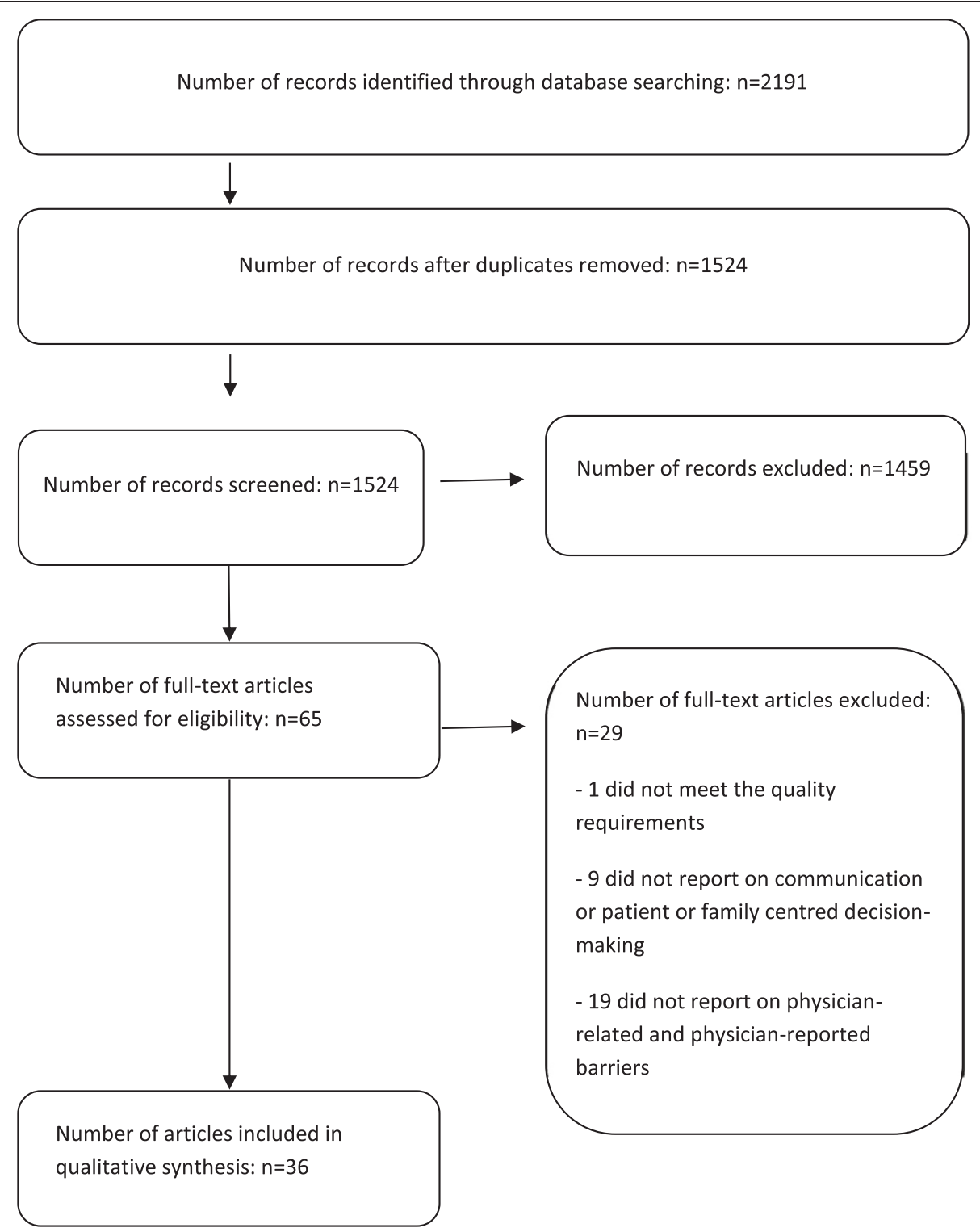

Figure 2 Study selection process.

Medium-quality evidence was found for the barrier that, owing to the hierarchy of the system, surgeons who are not fully aware of the patient's actual condition (that is, that further treatment may be futile) can slow down the team's decision-making process [21].

Preparing the patient and family for the dying process (QI 10)

One barrier found was that physicians are not taught how to recognise that a person is about to die (medium-quality evidence) [21] and have unrealistically high expectations about the patient's prognosis and effectiveness of ICU treatment (weak evidence) [42].

\section{Clarify and document the status of the patient's} advance directive (QI 16)

Physicians are uncertain about the legal standing of, and have no experience with, advance directives (weak evidence) [38].

\section{Establish and document clear, realistic, and} appropriate goals of care in consultation with the patient and family (QI 21)

Lack of familiarity with how to make a prognosis (medium-quality evidence) [15] and not knowing how to relate to families who pressure them to continue 
Table 1 Characteristics and quality assessment of included studies

\begin{tabular}{|c|c|c|c|c|c|}
\hline Study (yr) [ref] & Country & Study objective & Study design & Participants & $\begin{array}{l}\text { Quality } \\
\text { assessment }\end{array}$ \\
\hline \multicolumn{6}{|l|}{ Qualitative studies } \\
\hline Pattison et al. (2013) [15] & UK & $\begin{array}{l}\text { To explore the meaning of end-of-life care for } \\
\text { critically ill cancer patients, their families, } \\
\text { oncologists, palliative care specialists, critical } \\
\text { care consultants and nurses }\end{array}$ & $\begin{array}{l}\text { Qualitative, phenomenological, } \\
\text { in-depth interviews }\end{array}$ & 13 physicians & 9 \\
\hline Gutierrez (2012) [16] & USA & $\begin{array}{l}\text { To explore the experiences of critical care } \\
\text { nurses and physicians with advance directives } \\
\text { in an intensive care unit (ICU) to identify the } \\
\text { benefits and limitations of advance directives } \\
\text { and recommendations for improvement }\end{array}$ & $\begin{array}{l}\text { Descriptive ethnographic study } \\
\text { with interviews in a } 22 \text {-bed } \\
\text { medical/surgical ICU in a } \\
\text { large community hospital }\end{array}$ & $\begin{array}{l}7 \text { attending physicians, } \\
3 \text { fellow physicians }\end{array}$ & 6.5 \\
\hline
\end{tabular}

Barnato et al. (2012) [17] USA To explore norms of decision-making regarding life-sustaining treatments at 2 academic medical centres that contribute to opposite extremes of end-of-life ICU use

Schenker et al. (2012) [18] USA To describe whether and how comfort care was presented as an option in family conferences about treatment options, and to assess whether the strength of the physicians' belief that life support should be withdrawn was associated with the presentation of comfort care

Jox et al. (2012) [19] Germany To explore how clinicians themselves define medical futility, whom they think should assess this, how they justify performing futle treatment and how they comm patients and caregivers

Baggs et al. (2012) [20] USA To examine the role of the 'attending physician' in four adult ICUs and the consequences of role complexities for clinicians, as well as for patients complexities for clinicians, as well as for patient
and their families, particularly in the context and their families, particularly in
of end-of-life decision-making

To identify the challenges for health care professionals when moving from a recovery trajectory to an end-of-life trajectory in intensive care

Ahern et al. (2012) [22] Canada

Interview-based qualitative study conducted to identify what is important to physician trainees in the ICU and infer from this positive educational experiences for physician trainees

Assess the concordance between patients' code status preferences and their actual code status orders; compare patients/ surrogates and their physicians regarding

Mixed-methods study: family meetings, informal and forma interviews, and artefacts

Mixed-methods study of 72 audio-recorded family conferences about end-of-life treatment decisions

Qualitative mixed-methods approach at a large tertiary referral centre used to analyse protocols of used to analyse protocols of ethics consultation

and semistructured interviews academic hospital academic hospital with surgica, medical, cardiovascular and burn/trauma ICU, including observations of end-of-life discussions and interviews

Semistructured interviews in

2 ICUs in a large university-affiliated hospital in England

Qualitative approach of hermeneutic phenomenology semistructured interviews 
Table 1 Characteristics and quality assessment of included studies (Continued)

\begin{tabular}{|c|c|c|c|c|c|}
\hline & & $\begin{array}{l}\text { their respective assessments of most } \\
\text { important goals of care }\end{array}$ & & & \\
\hline Schwarze et al. (2010) [24] & USA & $\begin{array}{l}\text { To examine the culture and practice of surgeons } \\
\text { to assess attitudes and concerns regarding } \\
\text { advance directives for their patients who } \\
\text { undergo high-risk surgical procedures }\end{array}$ & $\begin{array}{l}\text { Qualitative study in trauma and } \\
\text { surgical critical care }\end{array}$ & 10 physicians & 7.5 \\
\hline Corke et al. (2009) [25] & Australia & $\begin{array}{l}\text { To examine attitudes of intensive care doctors to } \\
\text { advanced care planning and medical enduring } \\
\text { power of attorney }\end{array}$ & $\begin{array}{l}\text { Survey followed by open-ended } \\
\text { questions }\end{array}$ & 275 trainees and fellows & 7 \\
\hline Sibbald et al. (2007) [26] & Canada & $\begin{array}{l}\text { To explore how frontline ICU staff defines } \\
\text { medically futile care, to discover why they } \\
\text { provide it and to identify strategies that } \\
\text { might promote a more effective use of ICU } \\
\text { resources }\end{array}$ & $\begin{array}{l}\text { Qualitative interviews in } 16 \text { ICUs of } \\
\text { academic and community hospitals }\end{array}$ & 16 medical directors & 8 \\
\hline Beck et al. (2008) [27] & Germany & $\begin{array}{l}\text { To identify difficulties and uncertainties in } \\
\text { making decisions about withholding and } \\
\text { withdrawing mechanical ventilation among } \\
\text { intensive care physicians }\end{array}$ & Problem-centred interviews & $\begin{array}{l}28 \text { interviewees, } 4 \text { consultants, } \\
11 \text { senior registrars, } 13 \text { senior } \\
\text { house officers ( } 20 \text { of } 28 \text { were } \\
\text { specialists) }\end{array}$ & 9 \\
\hline Baggs et al. (2007) [28] & USA & $\begin{array}{l}\text { To clarify unit cultures surrounding end-of-life } \\
\text { decision-making in } 4 \text { US adult medical and } \\
\text { surgical ICUs }\end{array}$ & $\begin{array}{l}\text { Prospective ethnographic study of } \\
4 \text { adult ICUs in which a 6-member } \\
\text { research team used participant } \\
\text { observations, field notes, and } \\
\text { semistructured interviews of } \\
\text { health care providers as well } \\
\text { as patients and their families }\end{array}$ & 13 physicians & 8 \\
\hline White et al. (2007) [29] & USA & $\begin{array}{l}\text { To determine the nature and extent of shared } \\
\text { decision-making about end-of-life treatment in } \\
\text { ICUs, which factors are predictive of higher levels } \\
\text { of shared decision-making }\end{array}$ & $\begin{array}{l}\text { Mixed-methods study: ICU family } \\
\text { conferences in } 1 \text { county hospital, } \\
1 \text { university hospital and } 2 \\
\text { community hospitals, as well } \\
\text { as questionnaires to physicians }\end{array}$ & 35 physicians leading conferences & 8.5 \\
\hline Hsieh et al. (2006) [30] & USA & $\begin{array}{l}\text { To identify inherent tensions that arose during } \\
\text { family conferences in the ICU and the communication } \\
\text { strategies clinicians used in response }\end{array}$ & $\begin{array}{l}\text { Qualitative content analysis; } \\
\text { communication between family } \\
\text { members and physicians was } \\
\text { analysed using a dialectic } \\
\text { perspective in } 51 \text { family-clinician } \\
\text { conferences in } 4 \text { hospitals }\end{array}$ & 36 physicians who led the conferences & 8.5 \\
\hline Palda et al. (2005) [31] & Canada & $\begin{array}{l}\text { To explore the process of the provision of futile } \\
\text { care in Canadian ICUs }\end{array}$ & $\begin{array}{l}\text { Survey with closed- and open-ended } \\
\text { questions }\end{array}$ & 114 physicians & 6.5 \\
\hline West et al. (2005) [32] & USA & $\begin{array}{l}\text { To identify categories of expressions of } \\
\text { nonabandonment in the setting of ICU family } \\
\text { conferences concerning withdrawing life-sustaining } \\
\text { therapy or the delivery of bad news, and to develop } \\
\text { a conceptual model in which nonabandonment is } \\
\text { expressed }\end{array}$ & $\begin{array}{l}\text { Qualitative analysis of statements } \\
\text { of abandonment during family } \\
\text { conferences discussing } \\
\text { withholding/withdrawing of } \\
\text { treatment }\end{array}$ & $\begin{array}{l}35 \text { physicians leading the } \\
\text { conferences }\end{array}$ & 7.5 \\
\hline
\end{tabular}
identify strategies that withholding and intensive care physicians

clarify unit cultures surrounding end-of-Ife (1) 4 US adult medical and

4 adult ICUs in which a 6-member research team used participant observations, field notes, and semistructured interviews of as patients and their families

Mixed-methods study: ICU family community hospitals, as we questionnaires to physicians

specialists) 
Table 1 Characteristics and quality assessment of included studies (Continued)

Quantitative studies

Bülow et al. (2012) [33]

European countries
(6 countries)

To examine whether religion and religiosity are important to end-of-life decisions and

patient autonomy in the ICU

Schimmer et al. (2012) [34] Germany

Kübler et al. (2011) [35]

Poland

Weng et al. (2011) [36]

China

Kranidiotis et al. (2010) [37] Greece

Schaden et al. (2010) [38]

Austria

Westphal and McKee (2009) [39]

USA

Sprung et al. (2008) [40]

To determine the decision-making process of withholding and/or withdrawing of life-sustaining treatment in cardiac ICUs

$$
\text { in Germany }
$$

To analyse the attitudes of ICU physicians regarding decisions to forgo life-sustaining treatment for adult ICU patients

To document current attitudes and practices of ICU doctors in China dealing with issues that have strong ethical and moral dimensions; to make comparisons with these attitudes and practices reported by ICU doctors in Hong Kong and Europe

To study the frequency, type and rationale for limiting life support in Greek multidisciplinary ICUs, the clinical and demographic parameters associated with limiting life support, and the participation of relatives in the decision-making process

To explore Austrian intensive care physicians' experiences with, and their acceptance of, the new advance directives legislation 2 years after enactment

To examine differences between physicians and nurses regarding knowledge about advance directives and do-not-resuscitate orders, and the personal factors that underlie beliefs and practices related to the use of advance directives and do-not-resuscitate orders

To evaluate physician documentation and the reasoning, considerations and difficulties in end-of-life decision-making in ICUs

To study the frequency, rationale and process for withholding and withdrawing life-sustaining treatment in intensive care patients in Ireland
Structured questionnaires in 6 European countries, 143 ICUs

304 physicians

Questionnaire distributed to all heart surgery ICUs $(N=79)$ in Germany

35 clinical directors, 25 senior ICU physicians

Anonymous, written, structured questionnaire survey

315 participants, representing 54 ICUs in 30 cities in 21 of the

31 regions of China

Prospective observational study, with an anonymous questionnaire in 8 multidisciplinary, general

hospital-affiliated ICUs

Survey of all ICUs in Austria

139 participants

Survey

53 physicians

Prospective study of end-of-life practices and decisions in consecutive patients who died or were subject to any

imitation of life-saving

interventions in 37 ICUs in

17 European countries

Prospective observationa

study of all consecutive

patients admitted to ICU

who died or had life-sustaining

treatment limited 
Table 1 Characteristics and quality assessment of included studies (Continued)

\begin{tabular}{|c|c|c|c|c|c|}
\hline Nelson et al. (2006) [42] & USA & $\begin{array}{l}\text { To improve the understanding of educational } \\
\text { needs among residents caring for the critically ill }\end{array}$ & Survey & 184 physicians & 7 \\
\hline White et al. (2006) [43] & USA & $\begin{array}{l}\text { To determine how decisions are made to limit } \\
\text { life-sustaining treatment for critically ill patients } \\
\text { who lack both decision-making capacity and } \\
\text { surrogate decision makers }\end{array}$ & $\begin{array}{l}\text { Prospective longitudinal } \\
\text { cohort study }\end{array}$ & $\begin{array}{l}47 \text { physicians of patients } \\
\text { without decision-making } \\
\text { capacity and without a surrogate }\end{array}$ & 6 \\
\hline Moss et al. (2005) [44] & USA & $\begin{array}{l}\text { To assess the knowledge, skills and attitudes } \\
\text { that physicians and nurses who practice in West } \\
\text { Virginia's ICUs have concerning end-of-life care }\end{array}$ & Survey & 153 physicians & 6 \\
\hline Cohen et al. (2005) [45] & $\begin{array}{l}\text { European Countries } \\
\text { (17 countries) }\end{array}$ & $\begin{array}{l}\text { To examine the communication of end-of-life } \\
\text { decisions in Europe }\end{array}$ & $\begin{array}{l}\text { Prospective observational study } \\
\text { of } 4,248 \text { patients who had any } \\
\text { limitation of life-sustaining treatment } \\
\text { or died in } 37 \text { ICUs in } 17 \text { countries }\end{array}$ & $\begin{array}{l}\text { Physicians collected data on } \\
4248 \text { patients }\end{array}$ & 7 \\
\hline Élő et al. (2005) [46] & Hungary & $\begin{array}{l}\text { To study the factors associated with limiting } \\
\text { resuscitation in Hungary }\end{array}$ & Survey & 72 doctors & 7 \\
\hline Sinuff et al. (2004) [47] & $\begin{array}{l}\text { Canada, USA, } \\
\text { Sweden, Australia }\end{array}$ & $\begin{array}{l}\text { To study the rate of establishing do-not-resuscitate } \\
\text { directives, determinants and outcomes of those } \\
\text { directives for mechanically ventilated patients }\end{array}$ & Multicentre observational study & $\begin{array}{l}3,099 \text { critically ill patients admitted } \\
\text { to } 15 \text { ICUs, documentation attending } \\
\text { physicians' clinical judgements }\end{array}$ & 7 \\
\hline Yap et al. (2004) [48] & Hong Kong & $\begin{array}{l}\text { To examine ethical attitudes of intensive care } \\
\text { physicians in Hong Kong }\end{array}$ & Survey & 65 physicians & 7 \\
\hline Hariharan et al. (2003) [49] & West Indies & $\begin{array}{l}\text { To analyse the characteristics of moribund patients } \\
\text { in a surgical ICU and highlight the dilemmas inherent } \\
\text { in treating such patients }\end{array}$ & $\begin{array}{l}\text { Prospective collection of data } \\
\text { from patient records }\end{array}$ & $\begin{array}{l}\text { Data of patients recorded by } \\
\text { physicians of surgical ICU }\end{array}$ & 6 \\
\hline $\begin{array}{l}\text { Garland and Connors } \\
\text { (2007) [50] }\end{array}$ & Canada & $\begin{array}{l}\text { To quantify the influence that ICU staff physicians } \\
\text { have on decisions to limit life support for critically } \\
\text { ill patients }\end{array}$ & $\begin{array}{l}\text { Data prospectively collected in the } \\
13 \text {-bed medical ICU of a } 520 \text {-bed } \\
\text { urban university-affiliated teaching } \\
\text { hospital }\end{array}$ & 9 staff physicians & 7 \\
\hline
\end{tabular}


Table 2 Barriers with regard to physicians' knowledge

\begin{tabular}{|c|c|}
\hline Quality indicator no. $^{\mathrm{a}}$ & Barriers with regard to physicians' knowledge \\
\hline \multirow[t]{3}{*}{ General } & - Insufficient physician training in communication about end-of-life issues ${ }^{b}[42]$ \\
\hline & - Clinician reluctance to use opioids or sedatives because of concern about side effects ${ }^{\mathrm{b}}$ [42] \\
\hline & - Lack of education in palliative medicine ${ }^{\mathrm{b}}[44]$ \\
\hline 1 & - Involvement of surgeons slows down decision-making because they do not understand patient's situation ${ }^{\complement}$ [21] \\
\hline 2 & - Lack of communication skills of senior medical residents when interacting with colleagues ${ }^{\complement}$ [22] \\
\hline 5 & - No familiarity with skilled and timely communication ${ }^{c}[26]$ \\
\hline \multirow[t]{2}{*}{10} & - Not taught how to recognize that a person is about to die, no awareness of the process of dying ${ }^{c}[21]$ \\
\hline & - Unrealistic expectations by clinicians about patient prognosis or effectiveness of ICU treatment ${ }^{\mathrm{b}}$ [42] \\
\hline \multirow[t]{2}{*}{16} & - Physician uncertainty about the legal details of advance directives ${ }^{\mathrm{b}}[38]$ \\
\hline & - Physician lack of physician experience with advance directives ${ }^{b}[38]$ \\
\hline \multirow[t]{6}{*}{21} & - Lack of familiarity to make a prognosis ${ }^{\mathrm{c}}[15]$ \\
\hline & $\begin{array}{l}\text { - Not knowing how to deal with 'feeling helpless' with families pressuring ICU teams to withhold treatment or } \\
\text { when family members are upset about aggressiveness of care provided to their unwilling loved one }{ }^{c}[22]\end{array}$ \\
\hline & - Uncertainty concerning the services provided by local hospice programs and whom to refer to hospices ${ }^{\mathrm{b}}[44]$ \\
\hline & - No awareness of professional or local guidelines that related to provision of futile care ${ }^{\mathrm{b}}$ [31] \\
\hline & - Insufficient training in communication with patients and their families ${ }^{\mathrm{b}}[31]$ \\
\hline & $\begin{array}{l}\text { - Lack of discussion of ethical issues in medical programmes; lack of knowledge of ethical issues concerning } \\
\text { end-of-life decisions }{ }^{\mathrm{b}} \text { [48] }\end{array}$ \\
\hline \multirow[t]{2}{*}{22} & - No familiarity with defining futility and how to communicate futility to patients and their families ${ }^{\complement}$ [19] \\
\hline & - No knowledge of management of critical illness by referring specialists; confounding factors in decision-making ${ }^{c}$ [21] \\
\hline \multirow[t]{6}{*}{23} & - Conditioned that doing nothing or withdrawing treatment is not helping patient ${ }^{\complement}[19]$ \\
\hline & $\begin{array}{l}\text { - No familiarity with legal framework regarding end-of-life decisions, wrong conception that law prohibits withdrawal } \\
\text { of mechanical ventilation }{ }^{c}[27,36]\end{array}$ \\
\hline & - No awareness of end-of-life care guidelines ${ }^{\complement}[27]$ \\
\hline & - Not being at ease in talking to patients and their families about limitations of therapy ${ }^{\mathrm{b}}[36]$ \\
\hline & $\begin{array}{l}\text { - No familiarity with end-of-life decision-making ('good prognosis' and 'give it a go' often said because of no } \\
\text { familiarity with end-of-life decision-making) }{ }^{b}[25]\end{array}$ \\
\hline & $\begin{array}{l}\text { - Insufficient clinician training in techniques for forgoing life-sustaining treatment without causing patient } \\
\text { suffering }{ }^{\text {b }}[42]\end{array}$ \\
\hline
\end{tabular}

${ }^{a}$ Quality indicators for adequate communication and decision-making in the ICU as developed by Clarke and colleagues [11] and as outlined above in the Introduction. ${ }^{b}$ Barriers for which weak evidence was found. 'Barriers for which medium-quality evidence was found.

treatment or are upset by the aggressiveness of treatment given against their wishes were identified as barriers (medium-quality evidence) [22].

Help the patient and family assess the benefits and burdens of alternative treatment choices as the patient's condition changes (QI 22)

Referring specialists are not familiar with the management of the critical illnesses of ICU patients, which can lead to difficulties when changes in management have to be made (medium-quality evidence) [21].

Forgo life-sustaining treatments in a way that ensures patient and family preferences are elicited and respected (QI 23)
Not being aware of the laws applying to do-not-resuscitate status and the limitation of life-sustaining treatment or withdrawal of treatment (medium-quality evidence) [27,36], not being aware of end-of-life guidelines (medium-quality evidence) [27] and being conditioned to treat for recovery rather than to do nothing (medium-quality evidence) [19] were all identified as barriers.

\section{Barriers with regard to physicians' attitudes}

Barriers with regard to physicians' attitudes were identified for 11 of the 23 QIs. Strong evidence was found for eight specific barriers.

Meet as interdisciplinary team to discuss the patient's condition, clarify goals of treatment, and identify the patient's and family's needs and preferences (QI 1) 


\section{Table 3 Barriers with regard to physicians' attitudes}

\section{Quality indicator no.} Barriers with regard to physicians' attitudes

- Lack of consensus among the treating team in making end-of-life decisions, surgeons in the ICU do not want to give responsibility to other members of the clinical team, looking only at the small percentage of patients who survive, and one physician could push for futile treatment looking only at a small aspect of the patient's overall condition ${ }^{b}[20,26]$

- Perception by the critical care attending physician that the consulting specialist controls life-sustaining treatment decision-making ${ }^{c}$ [17]

- Physicians are overly sure of making the right decision themselves; they do not include patients in care decisions and consensus development ${ }^{c}[21,37]$

- Conflicting opinions of different attending physicians about prognosis and treatment and about recognition that death is a potential reality ${ }^{b}[15,20]$

Surgeon's disagreement with other consultants to accept futility treatment ${ }^{d}$ [49]

- Negative attitude towards relatives who want limitation of treatment ${ }^{d}$ [37]

- Family is thought not to understand end-of-life practice, family was considered not available, or physicians found discussion with relatives unnecessary ${ }^{d}$ [37]

- Palliative care input was limited to the very end of life, 'death is not usually expected', and narrow interpretation of when a patient is dying (that is, that a patient whose vital signs cannot be maintained despite maximal life-sustaining treatment is dying ${ }^{b}[15,17]$

- Physicians sometimes use language that seems to imply abandonment of their patients during the end-of-life decision-making process, as if withdrawal is the sole responsibility of the family, without mentioning another mode of care $^{\mathrm{d}}$ [32]

- Uneasiness in dealing with surrogate decision maker ${ }^{c}$ [22]

- Family is thought not to understand, family was not available, or physician found discussion unnecessaryc $[37,45]$

- Negative opinion of advance directives, often perceived as not preventing unwanted aggressive treatment (because of lack of communication with relatives) and lacking a level of specificity necessary to facilitate decision-making ${ }^{\mathrm{d}}[16]$

- Physicians' own ethical values regarding advance directives ${ }^{\mathrm{d}}$ [38]

- Physicians consider do-not-resuscitate orders paperwork, slow, and not applicable to situations related to dying at the ICU $[28]$

- Physicians are not aware of patients' preferences regarding do-not-resuscitate orders ${ }^{\mathrm{d}}$ [23]

- Physicians believe that do-not-resuscitate orders should not be applied ${ }^{d}$ [36]

- Most physicians only discuss do-not-resuscitate order when the prognosis is poor or when the patient's condition deteriorates ${ }^{c}[39,47]$

- Family dynamics and legal concerns were the most important concerns affecting physicians' decision to write or obtain a do-not-resuscitate order ${ }^{d}$ [39]

- The most important factor influencing do-not-resuscitate decisions was the opinion of the head of the department or the doctor in charge of the patient's care, not the wishes of the patient and/or the patient's family ${ }^{\mathrm{d}}$ [46]

- No acceptance that the patient is dying; opinion that life should be the foremost concern in end-of-life decision making and that patient's goal of care is to survive (surgeons); physicians cannot let patients die: "They regard life at any cost to be a success" (comment physician) ${ }^{b}[21,28,31,35]$

- Conflicting opinion about prognosis, medical uncertainty and focus on narrow physiologic objectives without recognition that the condition of the patient becomes terminal, reaching a point of futility with prolongation of dying; these are barriers limiting the amount of time left for appropriate decision-making ${ }^{\mathrm{b}}$ [15-17]

- Surgeons in the team want to continue life-sustaining treatment; they do not accept that they cannot go any further; they do not consider end-of-life discussions in the surgical ICU, which take place later in the patient's illness trajectory, often in a critical atmosphere ${ }^{b}[19,20]$

- Physicians are sure of making the right decisions themselves and do not include patients in care decisions and consensus development ${ }^{c}[21,37]$

- Think that families do not understand end-of-life practices, that families are not available, or that discussions about goals of care are unnecessary ${ }^{c}[37,45]$

- Think that time spent with family wastes time and energy when families want continuation of aggressive treatment or when there is disagreement or extended hesitation over a decision ${ }^{c}$ [22] 


\begin{tabular}{|c|c|}
\hline \multirow{6}{*}{22} & $\begin{array}{l}\text { - No appropriate communication strategy, no information-seeking, but instead arguing with patient } \\
\left.\text { and/or the patient's family or avoiding discussions with them as decision-centred strategy }{ }^{[} 30\right]\end{array}$ \\
\hline & $\begin{array}{l}\text { - Not eliciting of family's wishes or assessment of family's understanding of information; the family } \\
\text { is often more told than asked about the nature and context of end-of-life decisions }{ }^{c}[29,45]\end{array}$ \\
\hline & $\begin{array}{l}\text { - Feeling of loss of control of referred patients and not believing in giving up on patients are reasons } \\
\text { not to refer patients to hospice }{ }^{d}[44]\end{array}$ \\
\hline & - No recognition of patients' goals of care ${ }^{d}[23]$ \\
\hline & - Physicians find it easier to carry on with treatment than to discuss alternative goals of care ${ }^{c}$ [21] \\
\hline & $\begin{array}{l}\text { - Surgeons consider informed consent documentation as a contract for potentially burdensome } \\
\text { postoperative therapy after a difficult operation (for example, transplant, neurosurgery) }{ }^{d}[24]\end{array}$ \\
\hline \multirow[t]{15}{*}{23} & $\begin{array}{l}\text { - Concerns about omission of life-sustaining treatment are larger (missing something treatable, fear } \\
\text { of doing something wrong or limiting life-sustaining treatment for a patient who might survive) } \\
\text { than concerns about harm of administering life-sustaining treatment (such as iatrogenic harms, } \\
\text { prolonging dying, and treating patients against their preferences) }{ }^{b}[17,19]\end{array}$ \\
\hline & $\begin{array}{l}\text { - Having end-of-life care discussions or engaging in shared decision-making with the patient } \\
\text { and/or the patient's family is considered only when the physician believes that life support } \\
\text { should be withdrawn }{ }^{\text {b }}[18,29]\end{array}$ \\
\hline & $\begin{array}{l}\text { - Physicians' concerns about potential legal action taken by families due to forgoing life-sustaining } \\
\text { treatment; therefore, they follow families' wishes, even after reading patients' advance directives } \\
\text { and even when the medical staff uniformly feels that it is not medically appropriate because } \\
\text { treatment is futile } e^{c}[16,26,36,39,42]\end{array}$ \\
\hline & $\begin{array}{l}\text { - Physicians prefer their own ideas about the best interests of the patient, are more focused on } \\
\text { medical technical parameters concerning withholding or withdrawing therapy, and continue } \\
\text { treatment, not respecting the patient's and/or the patient's family's wishes or the patient's living } \\
\text { will to stop treatment }{ }^{c}[27,33,34,40]\end{array}$ \\
\hline & $\begin{array}{l}\text { - Diagnostic uncertainty or potential for reversibility of illness is justification for continuation of } \\
\text { treatment against the instructions in the patient's medical enduring power of attorney or the } \\
\text { patient's wishes for palliation }{ }^{c}[25,37]\end{array}$ \\
\hline & $\begin{array}{l}\text { - Unresponsiveness to treatment already offered is the main factor influencing the physician's decision } \\
\text { to withhold or withdraw therapy, not the patient's and/or the patient's family's request }{ }^{c}[37,40,41]\end{array}$ \\
\hline & - Doubts about the validity of the patient's wishes expressed earlier ${ }^{c}[25,27]$ \\
\hline & - Less respect for patients' wishes by surgeons compared to other ICU physicians ${ }^{\complement}$ [28] \\
\hline & $\begin{array}{l}\text { - Feeling of betrayal, unhappiness, disappointment and even culpability when family member confronts } \\
\text { physician with advance directives in the setting of prolonged life-sustaining treatment }{ }^{d}[24]\end{array}$ \\
\hline & - The treating physician considers death in the ICU as a personal failure ${ }^{d}$ [24] \\
\hline & $\begin{array}{l}\text { - Physician's distrust of the health care proxy's motivation to request forgoing life-sustaining treatment } \\
\text { and the family's underlying preferences }{ }^{d}[25]\end{array}$ \\
\hline & - Physician's distrust concerning the timing of the completion of the advance directive ${ }^{d}$ [25] \\
\hline & $\begin{array}{l}\text { - Physician's conception that medical enduring power of attorney and advance directives provide } \\
\text { indications or guidelines rather than a decision that has to be respected }{ }^{d}[25]\end{array}$ \\
\hline & $\begin{array}{l}\text { - Legal concerns or disagreements with other physicians about whether it is appropriate to write a } \\
\text { do-not-resuscitate order or withdraw treatment from patients who lack decision-making capacity and } \\
\text { do not have a surrogate decision maker }{ }^{\text {d }} \text { [4] }\end{array}$ \\
\hline & $\begin{array}{l}\text { - Personal values and beliefs of intensivists, more than comorbidities or the type of acute illness, } \\
\text { are barriers to forgoing life-sustaining treatment }{ }^{\text {[ }}[50]\end{array}$ \\
\hline
\end{tabular}

${ }^{a}$ Quality indicators for adequate communication and decision-making in the ICU as developed by Clarke and colleagues [11] and as outlined above in the Introduction. ${ }^{b}$ Barriers for which strong evidence was found. ${ }^{c}$ Barriers for which medium-quality evidence was found. ${ }^{\mathrm{d} B a r r i e r s}$ for which weak evidence was found.

There is a danger of lack of consensus among the treating team when the focus of the surgeon is on the small percentage of patients who will survive because of their treatment and not on the greater percentage who will not, as well as when ICU physicians focus on the particular aspect of the patient's condition which comes under their remit rather than on their overall condition and thus do not want to pass responsibility to other members of the clinical team who may have a more holistic perception of the patient's condition (strong evidence) [20,26]. Medium-strength evidence was found for the barriers that physicians are overly sure of making the right decision themselves and that they do not include nurses' opinions and 
Table 4 Barriers with respect to physicians' practice

\begin{tabular}{|c|c|}
\hline Quality indicator no. $^{\mathrm{a}}$ & Barriers with respect to physicians' practice \\
\hline General & - Competing demands for clinicians' time ${ }^{\mathrm{b}}[42]$ \\
\hline 1 & - Unavailability of attending physicians due to rotation systems ${ }^{\mathrm{c}}[22]$ \\
\hline \multirow[t]{2}{*}{2} & - Hierarchy under physicians is a barrier to their solving problems within the team before talking to the patient ${ }^{\complement}[22]$ \\
\hline & - Individual physicians' lack of holistic views ${ }^{c}[26]$ \\
\hline 7 & $\begin{array}{l}\text { - Physicians do not routinely check that family members understand the information they are given and do not discuss } \\
\text { the family's role in decision-making }{ }^{c}[29]\end{array}$ \\
\hline 10 & $\begin{array}{l}\text { - Low confidence in taking responsibility; physicians do not refer patients to hospice care, because the patient or the } \\
\text { patient's family does not accept that the patient is dying }{ }^{b}[44]\end{array}$ \\
\hline 15 & - Not actively recommending the creation of an advance directive ${ }^{\mathrm{b}}[38]$ \\
\hline \multirow[t]{5}{*}{21} & $\begin{array}{l}\text { - Low confidence in taking responsibility; the physician does not take responsibility for collaborative decision-making } \\
\text { with the dying patient and thus leaves the patient to die as if the patient has decided when to die }{ }^{c}[15]\end{array}$ \\
\hline & $\begin{array}{l}\text { - Low confidence in taking responsibility; the physician considers family requests for continued futile treatment as a } \\
\text { mandate and not as part of a normal communication and decision-making process }{ }^{c}[17,31]\end{array}$ \\
\hline & $\begin{array}{l}\text { - Low confidence in taking responsibility; the physician externalizes control of decision-making to patients, their families } \\
\text { and specialists, who they believe expect aggressive treatment }{ }^{c}[17]\end{array}$ \\
\hline & - Postponing decision-making until all treatment options are exhausted, until the last moment (surgeons) ${ }^{\complement}[28]$ \\
\hline & - No use of professional or local guidelines related to the provision of futile care ${ }^{b}[31]$ \\
\hline \multirow[t]{8}{*}{23} & - Lack of time and information are reasons to initiate life support, resulting in futile treatment ${ }^{c}[26]$ \\
\hline & $\begin{array}{l}\text { - Continuation of aggressive treatment is justified, because of lot of money is already invested in the patient, and availability } \\
\text { of resources }{ }^{\complement}[17]\end{array}$ \\
\hline & $\begin{array}{l}\text { - Aggressive care deemed to be appropriate because of no awareness among providers of existence of advance directive } \\
\text { or living will }{ }^{b}[16]\end{array}$ \\
\hline & $\begin{array}{l}\text { - Low confidence in taking responsibility; the rate of withholding and withdrawing therapy was reduced based upon } \\
\text { family's wishes }^{b}[35]\end{array}$ \\
\hline & - Considering withholding and withdrawing decisions inappropriately delayed ${ }^{\mathrm{b}}$ [37] \\
\hline & $\begin{array}{l}\text { - No support of an internal multidisciplinary committee or professional policies in cases involving patients who do not } \\
\text { have decision-making capacity or a surrogate }{ }^{b}[43]\end{array}$ \\
\hline & $\begin{array}{l}\text { - Low confidence in taking responsibility; when the patient's family insists that everything should be done for a patient } \\
\text { with a poor prognosis, physicians are less inclined to withdraw treatment than when the family insists on limitation of } \\
\text { therapy }^{\text {b }} \text { [48] }\end{array}$ \\
\hline & $\begin{array}{l}\text { - Low confidence in taking responsibility; high hopes of the family and their consistent requests to the surgeons } \\
\text { contribute to the continuation of therapy which was considered futile by at least two consultants }{ }^{\mathrm{b}}[49]\end{array}$ \\
\hline
\end{tabular}

${ }^{\mathrm{a}}$ Quality indicators for adequate communication and decision-making in ICU as developed by Clarke and colleagues [11] and as outlined above in the Introduction. ${ }^{\mathrm{b}}$ Barriers for which weak evidence was found. ${ }^{\mathrm{C}}$ Barriers for which medium-quality evidence was found.

patients' needs in making care decisions and developing a consensus [21,37].

\section{Address conflicts among the clinical team before meeting with the patient and/or family (QI 2)}

Disagreement and conflicting opinions about the patient's prognosis and treatment and the imminence of death by different attending physicians was found to be a barrier (strong evidence) $[15,20]$.

\section{Prepare the patient and family for the dying process} (QI 10)

A narrow interpretation of when a patient is dying, that is, when vital signs cannot be maintained despite maximal life-sustaining treatment and the consideration of palliative care as being appropriate only for the very end of life were both identified as barriers (strong evidence) $[15,17]$.

\section{Recognize the patient and family as the unit of care (QI 11)}

Medium-strength evidence was found for the barriers in which physicians feel uneasy dealing with surrogate decision makers [22] because they think that the family will not understand and feel that end-of-life discussions with relatives unnecessary $[37,45]$.

Initiate advance care planning with the patient and family (QI 15) 
Identified as barriers were (1) the physicians' personal ethical values and (2) their negative opinions of advance directives, which they consider inapplicable in emergencies and lacking a level of specificity (weak evidence) $[16,38]$.

\section{Clarify and document resuscitation orders (QI 18)}

We found medium-level evidence for the barrier that physicians discuss do-not-resuscitate orders only when the patient's prognosis is poor [39,47], and the most important factor influencing the decision to write a do-not-resuscitate order is the physician's opinion and not the wishes of the patient or the patient's family to stop treatment (weak evidence) [46]. The family's wish that a do-not-resuscitate order not be written and their concerns about the legality of the order are important in influencing a physician's decision (weak evidence) [39]. A physician's beliefs that do-not-resuscitate orders should not be applied (weak evidence) [36] and that do-not-resuscitate orders are a lot of paperwork or are not applicable to the situation of the dying patient (medium-quality evidence) [28] were also considered to be barriers.

\section{Establish and document clear, realistic, and appropriate goals of care in consultation with the patient and family (QI 21)}

We found strong evidence that physicians' personal beliefs and values can hinder the process of establishing and documenting clear, realistic and appropriate goals of care with the patient and family. Surgeons are trained to believe that the goal of treatment is the patient's survival. Physicians tend not to accept that a patient is dying and believe that the patient's life should be saved $[21,28,31,35]$. We also found strong evidence for the barrier that surgeons in particular want to continue life-sustaining treatment and that end-of-life discussions take place later in the surgical ICU than in the medical ICU $[19,20]$. Strong evidence was found that physicians' conflicting opinions about the patient's prognosis and their focus on narrow physiological objectives, without recognition that the condition of the patient has become terminal, are barriers to timely end-of-life discussions [15-17].

Physicians are sure of making the right decisions themselves without including patients in care decisions and without consensus development (medium-level evidence) $[21,37]$ and believe that families do not understand end-of-life practices, such that discussions about the goals of care are not necessary (medium-level evidence) $[37,45]$. Time spent with the family is considered as wasted when the family insists on futile treatment (medium-level evidence) [22]. Evidence was also found for the barrier that physicians do not use appropriate communication strategies in discussions with the patient or the patient's family, but either argue or avoid discussions (medium-level evidence) [30] or inform the patient or the patient's family only about the nature and context of the end-of-life decision and do not ask them about their wishes and preferences $[29,45]$.

Further, physicians do not recognize patients' goals of care, which are more related to quality of life related than to physicians' goals of their living longer (weak evidence) [23]. The physician's feeling of loss of control of referred patients and the physician's perceptions that doing nothing equals giving up on a patient are seen as reasons not to refer patients to hospices (weak evidence) [44].

\section{Help the patient and family assess the benefits and burdens of alternative treatment choices as the patient's condition changes (QI 22)}

Physicians find it easier to carry on with treatment than to discuss alternative goals of care (medium-strength evidence) [21], and surgeons consider informed consent to be a contract for potentially burdensome postoperative therapy after a difficult operation (for example, organ transplant, neurosurgery) (weak evidence) [24].

\section{Forgo life-sustaining treatments in a way that ensures patient and family preferences are elicited and respected (QI 23)}

Strong evidence was found for the barrier that physicians are more concerned that, by abandoning life-sustaining treatment, they might miss something which is treatable than that they might harm patients by prolonging life-sustaining treatment and the dying process or by treating patients against patients' preferences $[17,19]$. Strong evidence was also found for the barrier that only if physicians themselves believe that life support should be withdrawn will they consider end-of-life discussions and shared decision-making with the patient and/or the patient's family $[18,29]$.

Medium-strength evidence was found that physicians prefer their own ideas of what is in the best interest of the patient, focusing instead on clinical and technical parameters to decide on withholding or withdrawing therapy, and do not respect the wishes of the patient or the patient's family to stop therapy, even when there is a living will $[27,33,34,40]$. Further, medium-strength evidence was found for the barrier that, even when the team confirms that treatment is futile and inappropriate, physicians follow the family's wishes when the family wants to continue futile treatment out of concerns about legal action $[16,26,36,39,42]$. Medium-strength evidence was also found for the barrier that uncertainty regarding the patient's prognosis and the potential for reversibility of the 
patient's illness are used as justification for continuation of treatment against the patient's or the legal proxy's wishes for palliation [25,37]. We also found medium-strength evidence for the barriers that the main factor that influences the physician to forgo therapy is the patient's unresponsiveness to treatment already offered and not the requests of the patient or the patient's family [37,40,41]. Barriers to respecting an advance directives and medical enduring power of attorney expressing the patient's wish to forgo treatment are that physicians have doubts about the validity of advance directives (medium-quality evidence) $[25,27]$, distrust concerning the timeliness of an advance directive, feelings of betrayal when confronted with an advance directive (weak evidence) [24,25] and a perception that the medical enduring power of attorney and advance directive provide indications or guidelines rather than a decision that has to be respected (weak evidence) [25].

\section{Barriers with regard to physicians' practice}

Barriers with regard to physicians' practice were identified for 7 of the 23 QIs. Lack of confidence in taking responsibility for communication and patient- and familycentred decision-making was a barrier identified for QIs 10, 21 and 23.

Meet as interdisciplinary team to discuss the patient's condition, clarify goals of treatment, and identify the patient's and family's needs and preferences (QI 1)

Unavailability of attending physicians due to the rotation system was found to be a barrier with medium-strength evidence [22].

\section{Address conflicts among the clinical team before} meeting with the patient and/or family (QI 2)

Hierarchy within the team was seen as a barrier to solving problems before talking to the patient (mediumlevel evidence) [22]. Individual physicians' lack of a holistic view was also seen as a barrier (medium-quality evidence) [26].

Clarify the patient's and family's understanding of the patient's condition and goals of care at the beginning and end of each meeting (QI 7)

Physicians do not routinely check that family members understand the information they are given and fail to discuss the family's role in decision-making (medium-level evidence) [29].

Prepare the patient and family for the dying process (QI 10)
Lack of confidence in taking responsibility for referring a patient to a hospice, the physician does not do so because the family does not accept that the patient is dying (weak evidence) [44].

\section{Establish and document clear, realistic, and appropriate goals of care in consultation with the patient and family (QI 21)}

We found medium-strength evidence for physicians' lack of confidence in taking responsibility as a barrier to decision-making with the dying patient; instead, physicians continue life-sustaining treatments until the patient dies [15]. We found medium-strength evidence that ICU surgeons postpone decision-making until all treatment options have been exhausted, until the very last moment [28]. Medium-strength evidence was also found for other barriers related to lack of confidence to take responsibility. Physicians consider a family's request for futile treatment as a mandate and not as part of normal communication in the decision-making process $[17,31]$, and they externalize control for decision-making to patients, their families and consulting specialists, who they believe expect aggressive treatment [17].

\section{Forgo life-sustaining treatments in a way that ensures patient and family preferences are elicited and respected (QI 23)}

Medium-strength evidence was found for the barrier that lack of time and information are reasons to continue therapy, as is money already invested in the patient's care and the availability of resources (medium-strength evidence) [17].

Weak evidence was found for lack of confidence in taking responsibility; the rate of withholding or withdrawing therapy was reduced at the family's request [35]. Physicians are less inclined to withdraw treatment when the family insists that everything should be done than when the family asks for limited therapy [48]. A family's high expectations and consequent requests to the surgeon contribute to the continuation of therapy considered futile by at least two other consultants (weak evidence) [49].

\section{Discussion}

The RWJF Critical Care End-of-Life Peer Workgroup has identified seven specific domains of ICU palliative care quality comprising adequate communication within the team and with patients and families and patient- and family-centred decision-making. However, no systematic description and analysis of barriers to adequate communication and decision-making have been undertaken before. To our knowledge, our present review is the first time that self-reported barriers to providing quality end-of-life care 
in these two domains have been identified for the main professional actor in the ICU-the ICU physician.

In 36 empirical studies, we identified 90 different physician-related barriers to adequate communication and patient- and family-centred decision-making towards the end of the patient's life in intensive care as they relate to ICU physicians' knowledge and skills, attitudes and practices. With respect to physicians' knowledge and skills, strong evidence was found for physicians' lack of communication training and skills in general, including communication with colleagues, and in particular regarding the communication of the futility of further treatment to the patient and the patient's family. Among barriers with strong evidence related to the attitudes of physicians, we found the lack of consensus among the treating team in end-of-life decision-making, when surgeons and physicians focus only on the small percentage of patients who will survive and do not want to share responsibility with other members of the clinical team, to be a barrier to interdisciplinary team discussions. Disagreement between team members and conflicting opinions about the patient's prognosis and treatment and about the futility of treatment are all barriers to addressing conflict within the team. The narrow interpretation by physicians of when a patient is actually dying, preventing the provision of palliative care until the last moment, is a barrier to preparing the patient and the patient's family for the dying process. The personal beliefs and values of physicians hinder the process of establishing and documenting clear, realistic and appropriate goals of care with the patient and the patient's family. Surgeons and physicians are trained to believe the goal of treatment is to save the patient's life and therefore to resist acknowledging that the patient is dying. Regarding the decision to forgo life-sustaining therapy, we found that physicians were more worried that they might miss something treatable than that they might harm patients with the prolongation of treatment and the dying process, even when this was against the patient's preferences. They tended to favour their own views of what is in the best interest of the patient, focusing on clinical and technical parameters rather than respecting the wishes of the patient and the patient's family to forgo treatment. Related to physicians' practice, we found that physicians often report that they lack the confidence to take responsibility for the dying patient and therefore postpone decision-making about withholding or withdrawing of treatment until all treatment options have been exhausted, thus continuing treatment until the patient dies.

The results of our review indicate that the lack of communication skills among physicians, the weakness of their skills in prognostic estimation and their lack of knowledge about the relevant legal framework are all barriers to the provision of good end-of-life care to patients in the ICU. The barriers we found with regard to physicians' attitudes demonstrate that physicians often see their job as more to save patients' lives than to let patients die in the best possible way. When physicians have to make decisions on the withholding or withdrawing of life-sustaining treatment, they favour their own ideas and focus on narrow physiological, technical and clinical parameters rather than on asking patients and patients' families about preferences regarding treatment. This suggests a lack of a holistic view of the patient's situation and prevents an understanding of what the patient sees as being in his or her own best interests. Because physicians are inclined to continue providing life-sustaining treatment, they ignore the harm that this may inflict upon the patient, to ignore the wishes of the patient and the patient's family to stop treatment, and to ignore the fact that the patient is actually dying. This means that timely end-of-life discussions are not possible and that the patient's wishes and preferences for the last phase of life are not respected, and thus their suffering continues. Palliative care, if it is provided at all, is suspended until the very last moment.

In team meetings and conflicts, when different team members have different opinions about continuation of life-sustaining treatment, the opinion of the consultant that treatment should be continued takes precedence, even when other team members consider such treatment to be futile. This authoritarian attitude is a barrier that prevents the provision of good end-of-life care to patients in the ICU. When the patient's family wants futile treatment to be continued, physicians have concerns about fulfilling their legal obligations and follow the family's wishes. However, when the patient and the patient's family want to stop therapy, physicians often continue it even in many countries in which the law recognizes the right of the patient to refuse treatment. Enforcement of these laws seems to be deficient and should be strengthened. Physician-related barriers to practice reveal that physicians lack confidence in their own judgment that treatment is futile and postpone decision-making about withdrawal of life-sustaining treatment until all treatment options have been exhausted and consider the family's request to continue futile lifesustaining therapy as mandatory. They do not consider communication and decision-making in the last phase of the patient's life as a normal process whereby the wishes of the patient's family are discussed earlier and thus during the last moments of the patient's life consensus can be achieved about the futility of the life-sustaining treatment.

We compared our findings with the findings of studies on barriers to communication in end-of-life care or advance care planning perceived by general practitioners, to find out if those barriers reported by ICU physicians are specific to practice in ICUs. Some barriers were in line with the findings of a systematic review by Slort and colleagues [51] on barriers for general practitioners, 
such as 'general physicians' (GPs') lack of availability, and knowledge about palliative care, unpredictability of the patient's clinical course, not talking honestly to patients about end-of-life care issues and practice barriers, for example, difficulty in dealing with patients in denial and not spontaneously taking the initiative to contact patients. In a systematic review by De Vleminck and colleagues on GP barriers to engaging in advance care planning, doubt regarding the content and practical availability of living wills was identified as a barrier to initiating advance care planning [52]. However, the backgrounds of GPs and ICU physicians are quite different. The GPs are better trained in communication with the patient and in taking a holistic approach and might have a long-standing relationship with the patient and the patient's family. ICU physicians do not have that longstanding relationship but are confronted much more often than GPs with patients in the last phase of life, and these patients are often in a critical condition in which communication is already difficult. The findings of these two reviews $[51,52]$ and our present review emphasize all the more the need to address the ICU physician-related barriers to communication with patients towards the end of life.

Our review has some limitations. It done during the past ten years, and we excluded studies published before 2003. During the past ten years, however, much attention in the public and professional domains has been given to end-of-life care, especially in the ICU, and we expect that the most important barriers are included in the studies published during this period. The study was limited to studies published in the English or Dutch language, so there may be studies from other countries that we did not include. Moreover, by limiting this review to barriers related to and reported by physicians, we excluded barriers perceived by nurses, patients, patients' family members and other care providers, as well as structural and institutional factors, so an overall perspective of barriers in the two quality domains could not be achieved.

Our results suggest that ICU physicians need to be trained in using a holistic approach to treating patients at the end of life and in communication competencies. Undergraduate and postgraduate medical educators already see training in communication skills as essential. They also view training in the legal framework and ethical principles of health care as important, as well as defining the role and competencies of the physician who cares for patients towards the end of life; however, such training often is not fully implemented. Palliative care guidelines and support teams in ICUs could help the ICU team to trigger a learning process in caring for patients towards the end of life without the intention of handing over such care completely to the palliative care team. Such a palliative care support team could also help the ICU team, by meeting them together as an interdisciplinary team to address conflicts of opinion.
Further research is needed to investigate interventions and to develop guidelines and protocols helpful to overcoming ICU physician-related barriers regarding adequate communication and patient-centred decisionmaking towards the end of life. Also, research is needed regarding barriers related to and reported by patients, their family members, and other care providers, as well as with regard to structural and institutional barriers.

\section{Conclusions}

We identified 90 different barriers reported by ICU physicians themselves that stand in their way to providing quality end-of-life care with respect to communication and decision-making. These barriers are related to physicians' knowledge, attitudes and practices. It is necessary to address these different barriers to improve the quality of end-of-life care for patients and their families in the ICU. In addition to the perspectives of the physicians, it is important to examine the barriers related to and reported by patients and patients' relatives, as well as other health care providers, in the ICU.

\section{Key messages}

- Ninety different physician-related barriers for quality communication and patient- and family-centred decision-making in end-of-life care in ICUs were identified. These barriers were related to physicians' knowledge, attitudes and practices.

- Regarding physicians' knowledge, strong evidence was found for physicians' lack of training in skills related to communication with patients, patients' families and physicians' colleagues, including communication of the futility of further treatment, as a barrier.

- Regarding physicians' attitudes, strong evidence was found for multiple barriers. These barriers are physicians' focus on the small percentage of patients who will survive and not on the larger number who will not and therefore will have to undergo intensive care treatment before they die; physicians' personal beliefs and values and their focus on only clinical and technical parameters; physicians' training only to save the patient's life; and physicians' narrow interpretation of when a patient is actually dying.

- Regarding physicians' practice, strong evidence was found for physicians' lack of confidence in taking responsibility for the care of the dying patient.

- These barriers need to be addressed to improve the quality of end-of-life care for patients and their families. Next to the physicians' perspectives, it is important to examine the barriers related and reported by patients and their relatives, as well as other health care providers, in the ICU. 


\section{Additional file}

\section{Additional file 1: PubMed search strategy for MEDLINE.}

\section{Abbreviations}

GP: General physician; ICU: Intensive care unit; QI: Quality indicator; RWJF: Robert Wood Johnson Foundation.

\section{Competing interests}

The authors declare that they have no competing interests.

\section{Authors' contributions}

$\mathrm{MV}$ and $\mathrm{DH}$ acquired and analysed the data. All authors contributed to the conception of the study, interpretation of the data, drafting of the manuscript and revision of the manuscript critically for important intellectual content. All authors read and approved the final manuscript.

\section{Acknowledgements}

We acknowledge Jane Ruthven for English-language editing.

\section{Author details}

${ }^{1}$ End-of-Life Care Research Group, Vrije Universiteit Brussel (VUB) and Ghent University, Laarbeeklaan 103, B-1090 Brussels, Belgium. ²Department of Medical Oncology, Ghent University, De Pintelaan 185, B-9000 Ghent, Belgium.

Received: 25 June 2014 Accepted: 20 October 2014

Published online: 18 November 2014

\section{References}

1. Teno JM, Gozalo PL, Bynum JP, Leland NE, Miller SC, Morden NE, Scupp T, Goodman DC, Mor V: Change in end-of-life care for Medicare beneficiaries: site of death, place of care, and health care transitions in 2000, 2005, and 2009. JAMA 2013, 309:470-477.

2. The SUPPORT Principal Investigators: A controlled trial to improve care for seriously ill hospitalized patients: the study to understand prognoses and preferences for outcomes and risks of treatments (SUPPORT). JAMA 1995, 274:1591-1598.

3. Piers RD, Azoulay E, Ricou B, Dekeyser Ganz F, Decruyenaere J, Max A, Michalsen A, Maia PA, Owczuk R, Rubulotta F, Depuydt P, Meert A, Reyners A, Aquilina A, Bekaert M, Van Den Noortgate N, Schrauwen W, Benoit D, for the APPROPRICUS Study Group of the Ethics Section of the ESICM: Perceptions of appropriateness of care among European and Israeli intensive care unit nurses and physicians. JAMA 2011, 306:2694-2703.

4. Nelson JE, Cox CE, Hope AA, Carson SS: Chronic critical illness. Am J Respir Crit Care Med 2010, 182:446-454

5. Cox CE, Martinu T, Sathy SJ, Clay AS, Chia J, Gray AL, Olsen MK, Govert JA, Carson SS, Tulsky JA: Expectations and outcomes of prolonged mechanical ventilation. Crit Care Med 2009, 37:2888-2894. quiz 2904.

6. Nelson JE, Puntillo KA, Pronovost PJ, Walker AS, McAdam JL, llaoa D, Penrod $\mathrm{J}$ : In their own words: patients and families define high-quality palliative care in the intensive care unit. Crit Care Med 2010, 38:808-818.

7. World Health Organisation: WHO Definition of Palliative Care. [http://www who.int/cancer/palliative/definition/en/] (accessed 24 November 2014).

8. Davidson JE, Powers K, Hedayat KM, Tieszen M, Kon AA, Shepard E, Spuhler V, Todres ID, Levy M, Barr J, Hirsch G, Armstrong D: Clinical practice guidelines for support of the family in the patient-centered intensive care unit: American College of Critical Care Medicine Task Force 2004-2005. Crit Care Med 2007, 35:605-622.

9. Nelson JE, Brasel KJ, Campbell ML, Curtis JR, Mosenthal AC, Puntillo KA, Bassett R, Weissman DE, for the IPAL-ICU (Improving Palliative Care in the ICU) Project: Defining Standards for ICU Palliative Care: A Brief Review from the IPAL-ICU Project [Monograph]. 2010 [http://ipal.capc.org/downloads/ipal-icudefining-standards-for-icu-palliative-care.pdf] (accessed 24 November 2014).

10. Nelson JE: Identifying and overcoming the barriers to high-quality palliative care in the intensive care unit. Crit Care Med 2006, 34(11 Suppl):S324-S331.

11. Clarke EB, Curtis JR, Luce JM, Levy M, Danis M, Nelson J, Solomon MZ, for the Robert Wood Johnson Foundation Critical Care End-of-Life Peer
Workgroup Members: Quality indicators for end-of-life care in the intensive care unit. Crit Care Med 2003, 31:2255-2262

12. Cabana MD, Rand CS, Powe NR, Wu AW, Wilson MH, Abboud PA, Rubin HR: Why don't physicians follow clinical practice guidelines? A framework for improvement. JAMA 1999, 282:1458-1465

13. Critical Appraisal Skills Programme: 10 questions to help you make sense of qualitative research. 31 May 2013 [http://media.wix.com/ugd/ dded87_951541699e9edc71ce66c9bac4734c69.pdf] (accessed 24 November 2014)

14. Center for Evidence-Based Management: Critical appraisal of a survey. [http://www.cebma.org/wp-content/uploads/Critical-Appraisal-Questionsfor-a-Survey.pdf] (accessed 24 November 2014).

15. Pattison N, Carr SM, Turnock C, Dolan S: 'Viewing in slow motion': patients', families', nurses' and doctors' perspectives on end-of-life care in critical care. J Clin Nurs 2013, 22:1442-1454.

16. Gutierrez KM: Advance directives in an intensive care unit: experiences and recommendations of critical care nurses and physicians. Crit Care Nurs Q 2012, 35:396-409

17. Barnato $A E$, Tate JA, Rodriguez KL, Zickmund SL, Arnold RM: Norms of decision making in the ICU: a case study of two academic medical centers at the extremes of end-of-life treatment intensity. Intensive Care Med 2012, 38:1886-1896.

18. Schenker Y, Tiver GA, Hong SY, White DB: Association between physicians' beliefs and the option of comfort care for critically ill patients. Intensive Care Med 2012, 38:1607-1615.

19. Jox RJ, Schaider A, Marckmann G, Borasio GD: Medical futility at the end of life: the perspectives of intensive care and palliative care clinicians. J Med Ethics 2012, 38:540-545.

20. Baggs JG, Schmitt MH, Prendergast TJ, Norton SA, Sellers CR, Quinn JR, Press N: Who is attending? End-of-life decision making in the intensive care unit. J Palliat Med 2012, 15:56-62.

21. Coombs MA, Addington-Hall J, Long-Sutehall $\mathrm{T}$ : Challenges in transition from intervention to end of life care in intensive care: a qualitative study. Int J Nurs Stud 2012, 49:519-527.

22. Ahern SP, Doyle TK, Marquis F, Lesk C, Skrobik Y: Critically ill patients and end-of-life decision-making: the senior medical resident experience. Adv Health Sci Educ Theory Pract 2012, 17:121-136.

23. Gehlbach TG, Shinkunas LA, Forman-Hoffman VL, Thomas KW, Schmidt GA Kaldjian LC: Code status orders and goals of care in the medical ICU. Chest 2011, 139:802-809.

24. Schwarze ML, Bradley CT, Brasel KJ: Surgical "buy-in": the contractual relationship between surgeons and patients that influences decisions regarding life-supporting therapy. Crit Care Med 2010, 38:843-848.

25. Corke C, Milnes S, Orford N, Henry MJ, Foss C, Porter D: The influence of medical enduring power of attorney and advance directives on decision-making by Australian intensive care doctors. Crit Care ResusC 2009, 11:122-128.

26. Sibbald R, Downar J, Hawryluck L: Perceptions of "futile care" among caregivers in intensive care units. CMAJ 2007, 177:1201-1208.

27. Beck S, van de Loo A, Reiter-Theil S: A "little bit illegal"? Withholding and withdrawing of mechanical ventilation in the eyes of German intensive care physicians. Med Health Care Philos 2008, 11:7-16.

28. Baggs JG, Norton SA, Schmitt MH, Dombeck MT, Sellers CR, Quinn JR: Intensive care unit cultures and end-of-life decision making. J Crit Care 2007, 22:159-168.

29. White DB, Braddock CH, Bereknyei S, Curtis JR: Toward shared decision making at the end of life in intensive care units: opportunities for improvement. Arch Intern Med 2007, 167:461-467.

30. Hsieh HF, Shannon SE, Curtis JR: Contradictions and communication strategies during end-of-life decision making in the intensive care unit. J Crit Care 2006, 21:294-304.

31. Palda VA, Bowman KW, McLean RF, Chapman MG: "Futile" care: Do we provide it? Why? A semistructured, Canada-wide survey of intensive care unit doctors and nurses. J Crit Care 2005, 20:207-213.

32. West HF, Engelberg RA, Wenrich MD, Curtis JR: Expressions of nonabandonment during the intensive care unit family conference. J Palliat Med 2005, 8:797-807

33. Bülow HH, Sprung CL, Baras M, Carmel S, Svantesson M, Benbenishty J, Maia PA, Beishuizen A, Cohen S, Nalos D: Are religion and religiosity important to end-of-life decisions and patient autonomy in the ICU? The Ethicatt study. Intensive Care Med 2012, 38:1126-1133. 
34. Schimmer C, Gorski A, Özkur M, Sommer SP, Hamouda K, Hain J, Aleksic I, Leyh R: Policies of withholding and withdrawal of life-sustaining treatment in critically ill patients on cardiac intensive care units in Germany: a national survey. Interact Cardiovasc Thorac Surg 2012, 14:294-299.

35. Kübler A, Adamik B, Lipinska-Gediga M, Kedziora J, Strozecki L: End-of-life attitudes of intensive care physicians in Poland: results of a national survey. Intensive Care Med 2011, 37:1290-1296.

36. Weng L, Joynt GM, Lee A, Du B, Leung P, Peng J, Gomersall CD, Hu X, Yap HY, the Chinese Critical Care Ethics Group: Attitudes towards ethical problems in critical care medicine: the Chinese perspective. Intensive Care Med 2011, 37:655-664.

37. Kranidiotis G, Gerovasili V, Tasoulis A, Tripodaki E, Vasileiadis I, Magira E, Markaki V, Routsi C, Prekates A, Kyprianou T, Clouva-Molyvdas PM, Georgiadis G, Floros I, Karabinis A, Nanas S: End-of-life decisions in Greek intensive care units: a multicenter cohort study. Crit Care 2010, 14:R228.

38. Schaden E, Herczeg P, Hacker S, Schopper A, Krenn CG: The role of advance directives in end-of-life decisions in Austria: survey of intensive care physicians. BMC Med Ethics 2010, 11:19

39. Westphal DM, McKee SA: End-of-life decision making in the intensive care unit: physician and nurse perspectives. Am J Med Qual 2009, 24:222-228.

40. Sprung CL, Woodcock T, Sjokvist P, Ricou B, Bulow HH, Lippert A, Maia P Cohen S, Baras M, Hovilehto S, Ledoux D, Phelan D, Wennberg E, Schobersberger W: Reasons, considerations, difficulties and documentation of end-of-life decisions in European intensive care units: the ETHICUS Study. Intensive Care Med 2008, 34:271-277.

41. Collins N, Phelan D, Marsh B, Sprung CL: End-of-life care in the intensive care unit: the Irish Ethicus data. Crit Care Resusc 2006, 8:315-320.

42. Nelson JE, Angus DC, Weissfeld LA, Puntillo KA, Danis M, Deal D, Levy MM, DJ C, for the Critical Care Peer Workgroup of the Promoting Excellence in End-of-Life Care Project: End-of-life care for the critically ill: a national intensive care unit survey. Crit Care Med 2006, 34:2547-2553.

43. White DB, Curtis JR, Lo B, Luce JM: Decisions to limit life-sustaining treatment for critically ill patients who lack both decision-making capacity and surrogate decision-makers. Crit Care Med 2006, 34:2053-2059.

44. Moss AH, Demanelis AR, Murray J, Jack J: Barriers to quality end-of-life care in West Virginia ICU units: physicians' and nurses' prospectives. W V Med J 2005, 101:200-204

45. Cohen S, Sprung C, Sjokvist P, Lippert A, Ricou B, Baras M, Hovilehto S, Maia P, Phelan D, Reinhart K, Werdan K, Bulow HH, Woodcock TT: Communication of end-of-life decisions in European intensive care units. Intensive Care Med 2005, 31:1215-1221.

46. Élő G, Diószeghy C, Dobos M, Andorka M: Ethical considerations behind the limitation of cardiopulmonary resuscitation in Hungary-the role of education and training. Resuscitation 2005, 64:71-77.

47. Sinuff T, Cook DJ, Rocker GM, Griffith LE, Walter SD, Fisher MM, Dodek PM, Sjokvist P, McDonald E, Marshall JC, Kraus PA, Levy MM, Lazar NM, Guyatt GH: DNR directives are established early in mechanically ventilated intensive care unit patients. Can J Anaesth 2004, 51:1034-1041.

48. Yap HY, Joynt GM, Gomersall CD: Ethical attitudes of intensive care physicians in Hong Kong: questionnaire survey. Hong Kong Med J 2004, 10:244-250.

49. Hariharan S, Moseley HS, Kumar AY, Walrond ER, Jonnalagadda R: Futility-of-care decisions in the treatment of moribund intensive care patients in a developing country. Can J Anaesth 2003, 50(8):847-852.

50. Garland A, Connors AF: Physicians' influence over decisions to forego life support. J Palliat Med 2007, 10:1298-1305.

51. Slort W, Schweitzer BP, Blankenstein AH, Abarshi EA, Riphagen II, Echteld MA, Aaronson NK, van der Horst $H$, Deliens L: Perceived barriers and facilitators for general practitioner-patient communication in palliative care: a systematic review. Palliat Med 2011, 25:613-629.

52. De Vleminck A, Houttekier D, Pardon K, Deschepper R, Van Audenhove C, Vander Stichele R, Deliens L: Barriers and facilitators for general practitioners to engage in advance care planning: A systematic review. Scand J Prim Health Care 2013, 31:215-226.

doi:10.1186/s13054-014-0604-z

Cite this article as: Visser et al:: Physician-related barriers to

communication and patient- and family-centred decision-making towards the end of life in intensive care: a systematic review. Critical Care 2014 18:604

\section{Submit your next manuscript to BioMed Central and take full advantage of:}

- Convenient online submission

- Thorough peer review

- No space constraints or color figure charges

- Immediate publication on acceptance

- Inclusion in PubMed, CAS, Scopus and Google Scholar

- Research which is freely available for redistribution 